\title{
OLHARES SOBRE A CIDADE - DEIXANDO MARCAS EM MOSAICO
}

\author{
MEDEIROS, Rodrigo Martins ${ }^{1}$. \\ SILVA, Silemar Maria de Medeiros da. ${ }^{2}$
}

O projeto Olhares sobre a cidade: deixando marcas em mosaico, aprovado pelo edital 169/2014 vêm para discutir como as pessoas, em específico os habitantes da cidade de Criciúma, a partir do que veem na sua cidade e o que esta tem a oferecer referente a patrimônio cultural material e imaterial. O objetivo desta escrita é apresentar alguns resultados obtidos na pesquisa de setembro de 2014 até abril de 2015. Partindo da compreensão de que muitas vezes, na medida em que certas regiões obtêm progresso econômico e social, há uma tendência de perdas relacionadas a patrimônio cultural e histórico, propomos algumas reflexões. Essa tendência de perdas com relação à história local, por exemplo, pode acontecer por inúmeros motivos: seja por falta de identificação dos habitantes com estes patrimônios, descaso das autoridades ou um distanciamento de gerações que se afastam de seus lugares de origem, entre outras. A sociedade muitas vezes vê no "novo" uma esperança para a solução de seus problemas, esquecendo, geralmente, o que esta mesma sociedade vivenciou no seu passado. Neste sentido, o presente artigo vem com o desafio de dar visibilidade ao patrimônio histórico e cultural, no intuito de conscientizar a comunidade de que é importante reconhecer sua(s) identidade(s), sob a ameaça de ser sobrepujada por uma realidade globalizada ou mesmo a ideia de universalidade.

Atuando em meio a este contexto o projeto: Olhares sobre a cidade: deixando marcas em mosaico, parte de uma parceria entre a Universidade e a comunidade em geral, a Associação Feminina de Criciúma (AFASC) no seu espaço chamado Oficina de Mosaico, local em que foram desenvolvidas as peças de mosaico para o Parque das Nações, localizado no bairro Próspera Criciúma SC, conforme consta no projeto aprovado pelo Edital nํㅗ 169/2014 -

\footnotetext{
${ }^{1}$ Acadêmico bolsista Gedest

${ }^{2}$ Prof $^{\mathrm{a}} \mathrm{MSc}-$ Unesc
} 
FUMDES. A fala de Leandro Konder, pode se fazer como uma síntese da ideia central do projeto:

\begin{abstract}
As cidades têm assumido características muito perversas, tornaramse inumanas e, se não soubermos transformá-las, elas tenderão naturalmente a nos arrastar para sucessivas catástrofes. Podemos, contudo, empreender as mudanças necessárias. E, para agir, para podermos mobilizar coletivamente nossas energias no sentido de encaminhar modificações urgentes possíveis, não podemos nos prender à imagem da cidade como um inferno. Precisamos reconhecer na realidade da cidade os pontos em que podemos nos apoiar para começar a atuar sobre ela transformadoramente. (KONDER, 1994, p. 79)
\end{abstract}

Para reconhecermos na realidade da cidade os pontos em que podemos nos apoiar, conforme defende Konder, pontuamos como intenção primeira dessa proposta, ampliar olhares pesquisadores sobre a cidade, com 0 desafio de um encontro que se soma a pesquisa com diferentes pessoas de que dela fazem parte - enquanto aponta-se uma reflexão sobre a cidade, na perspectiva de suas marcas/ identidade cultural. Situam-se aqui os moradores dos bairros da cidade como participantes fundamentais nesta pesquisa, pois será principalmente destes que virão os dados para os desenhos que comporão os mosaicos. Trata-se de uma pesquisa que encontra-se ainda em andamento, portanto o que apresentamos é um resultado parcial dos desafios desse projeto.

A partir do trabalho em três dos bairros mapeados na pesquisa (a princípio estima-se um número maior, embora esse número não esteja definido no projeto) os dados serão apresentados e analisados na luz de uma teoria que possibilita maior compreensão dos conceitos de identidade cultural, arte, cidade e mosaico. Trata-se, assim, de uma pesquisa qualitativa na qual visa um recorte de uma realidade a ser melhor compreendida. A metodologia se baseia em relatos de pessoas que possam fornecer dados historicamente significativos, geralmente moradores mais antigos, e a partir daí, elaborar a arte - desenhos que serão transformados em mosaicos -, a serem estampadas nas escadarias da cidade. Nesse sentido, a presente investigação se caracteriza enquanto uma pesquisa de campo, ou seja: 
[..].Concebemos campo de pesquisa como o recorte que 0 pesquisador faz em termo de espaço, representando uma realidade empírica a ser estudada a partir das concepções teóricas que fundamentam o objeto da investigação. A título de exemplo, podemos citar, entre outros, o seguinte recorte: o estudo da percepção das condições de vida dos moradores de um determinado bairro ou de uma favela. Para esse estudo, a favela ou o bairro escolhido corresponde a um campo empiricamente determinado. (MINAYO, 2002, p 52)

No bairro São Cristóvão (Criciúma, Santa Catarina) foi dado o primeiro passo na execução do projeto. Os encontros com as pessoas acontecem geralmente em suas residências, e são marcados a partir de indicação dos próprios moradores, considerando os mais antigos ou os agentes comunitários: pessoas que participam ativamente da comunidade. Quando perguntados sobre o que mais Ihes marcava a memória no seu bairro, os moradores do Bairro São Cristóvão citaram principalmente as atividades da indústria carbonífera, como a via férrea que passava no local, em meio a um corte que foi feito entre os morros antes ali presentes. Fato que gerou o apelido "região do corte" ao local onde se localiza a escadaria. Foi citada também a caixa de escolha do carvão e as entradas das minas, sendo uma delas habitada por um andarilho chamado "Bronze" que gerava medo nas crianças da época. Crianças estas que costumavam brincar em uma região cheia de eucaliptos, que possibilitavam várias atividades. As somas de algumas falas foram servindo de suporte para a representação gráfica do local, conforme podemos perceber na fala de Claudionor da Silva:

Tinha uma mina, a mina do Bronze, que quando nós éramos crianças, todo mundo tinha medo de ir lá, porque nessa mina morava um andarilho, que era conhecido como Bronze. Nossos pais diziam que se a gente não se comportasse ele iria nos pegar... (Claudionor da Silva, 11 de outubro de 2014)

A religiosidade também era algo marcante para a época, sendo declarado feriado nas datas de comemoração a santos. Casas populares que eram localizadas a margem da via férrea também foram lembradas. Todos estes elementos contribuíram para a elaboração dos desenhos. 
Figura 1 - Desenho escadaria bairro São Cristóvão - Criciúma, Santa Catarina.

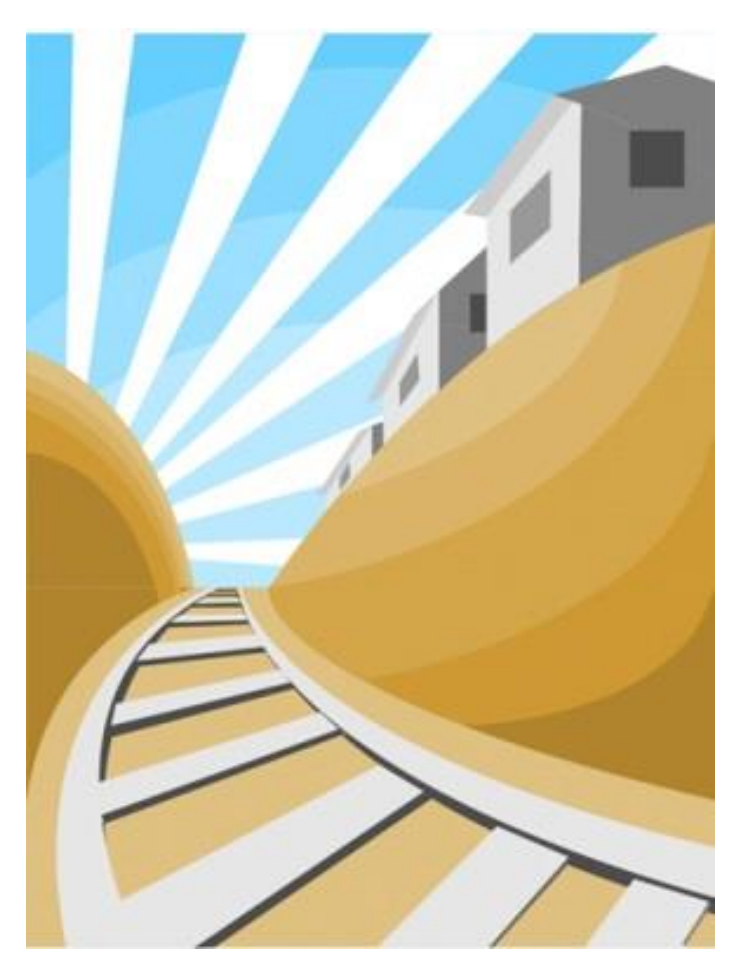

Fonte: acervo do pesquisador.

Os desenhos elaborados são colocados nas escadarias através de uma simulação no editor de fotos Adobe Photoshop e também do Corel Draw e apresentados aos moradores que cederam as entrevistas para a aprovação dos mesmos. Uma metodologia de pesquisa que chamamos de devolutiva. Nesse momento os moradores podem acrescentar ou retirar algumas falas ou sugestões.

Figura 2 - Projeto escadaria bairro São Cristóvão - Criciúma, Santa Catarina. 


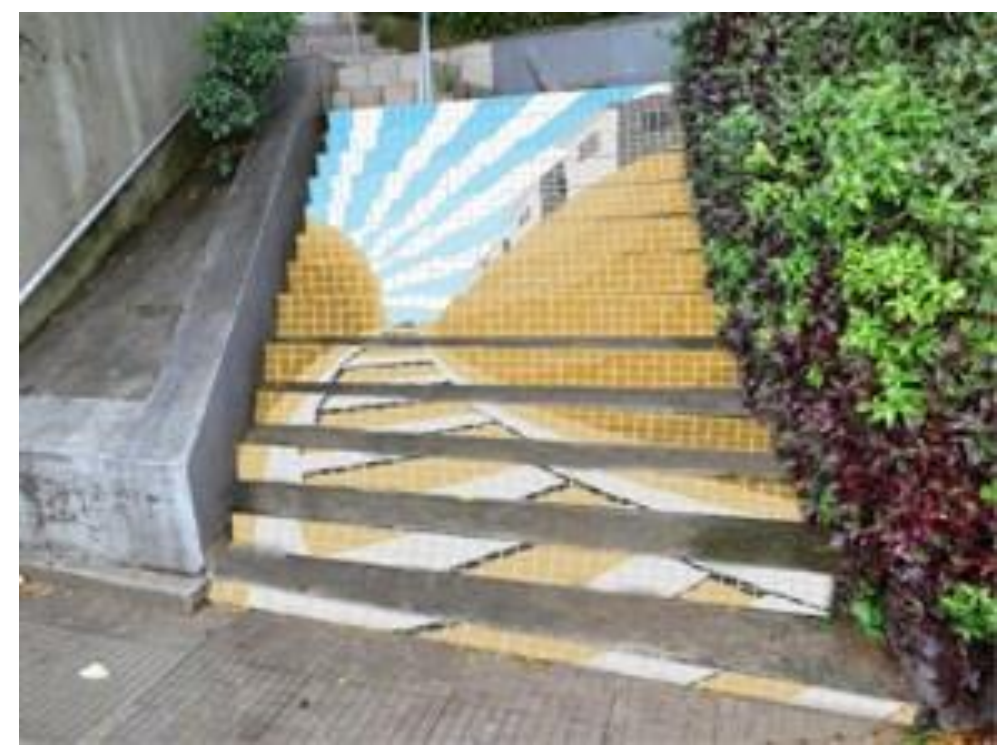

Fonte: acervo do pesquisador.

As escadarias do Bairro São Cristóvão têm uma peculiaridade: ela se apresenta em 3 vãos de escadarias. Nesse sentido foram elaborados 3 desenhos, os quais viraram os projetos que foram analisados e aprovados pelos moradores. No primeiro desenho o corte e as casas são evidenciadas, já no segundo lance de escadaria temos a via férrea, os eucaliptos e o bastão representando o São Cristóvão, santo que dá nome ao bairro.

Figura 3 - Desenho escadaria bairro São Cristóvão - Criciúma, Santa Catarina.

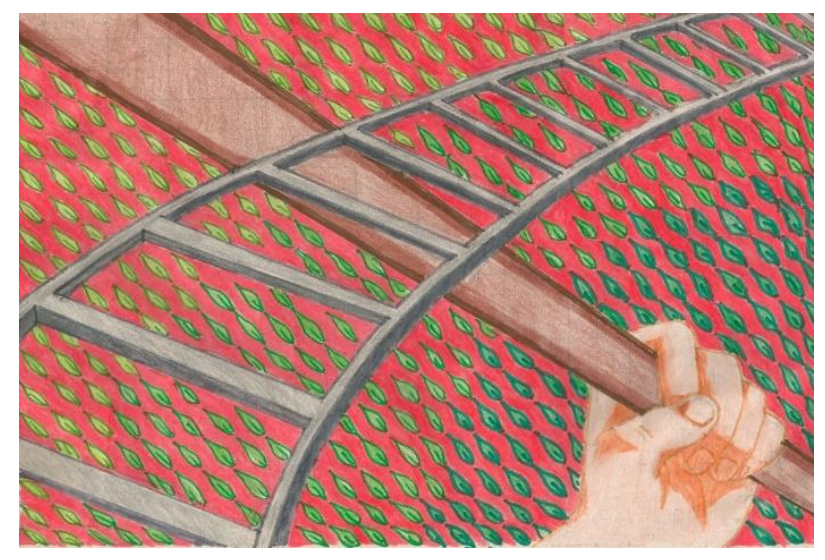

Fonte: acervo do pesquisador.

O desenho apresenta-se na escadaria dando a ilusão da obra concretizada, enquanto recebe a aprovação dos moradores. Depois da arte 
final, mais uma visita no bairro acontece e os desenhos com seus projetos já estampados nas escadarias é mostrado e os moradores dão suas opiniões sobre a pesquisa.

Figura 4 - Projeto escadaria bairro São Cristóvão - Criciúma, Santa Catarina.

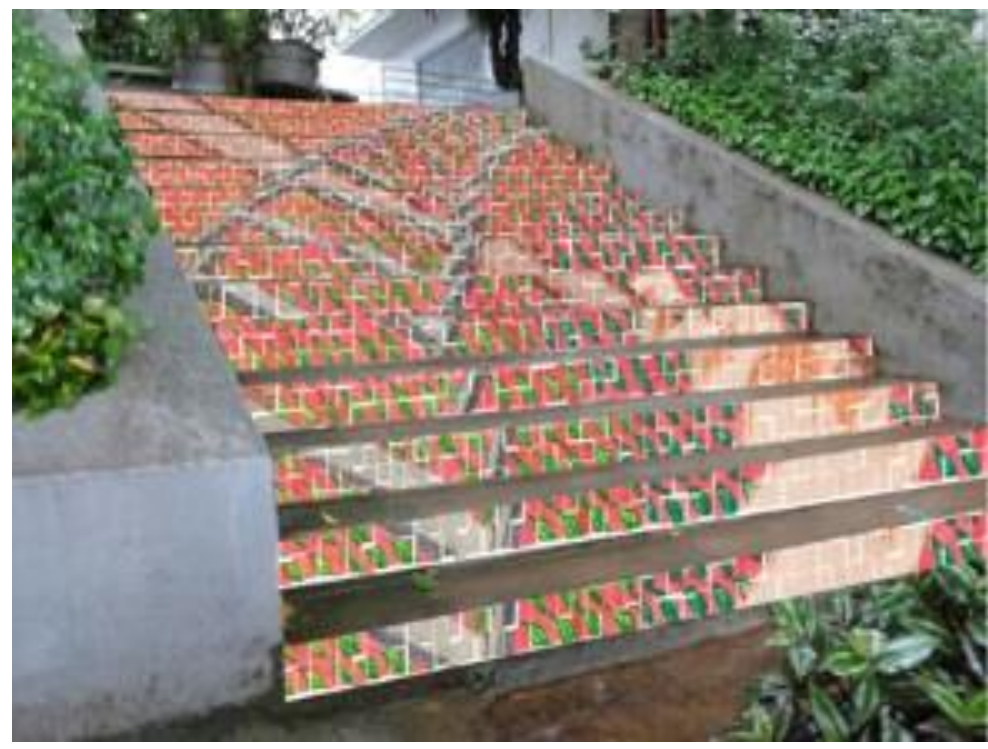

Fonte: acervo do pesquisador.

O terceiro lance de escadaria do Bairro São Cristóvão estampa um horizonte promissor com o poder do trem, um personagem que corta a cidade na sua história de Capital do Carvão. Não corta mais pelo mesmo caminho, mas ainda persiste passando por outros bairros como Pinheirinho, Cristo Redentor, Rio Maina e Verdinho.

Figura 5 - Desenho escadaria bairro São Cristóvão - Criciúma, Santa Catarina. 


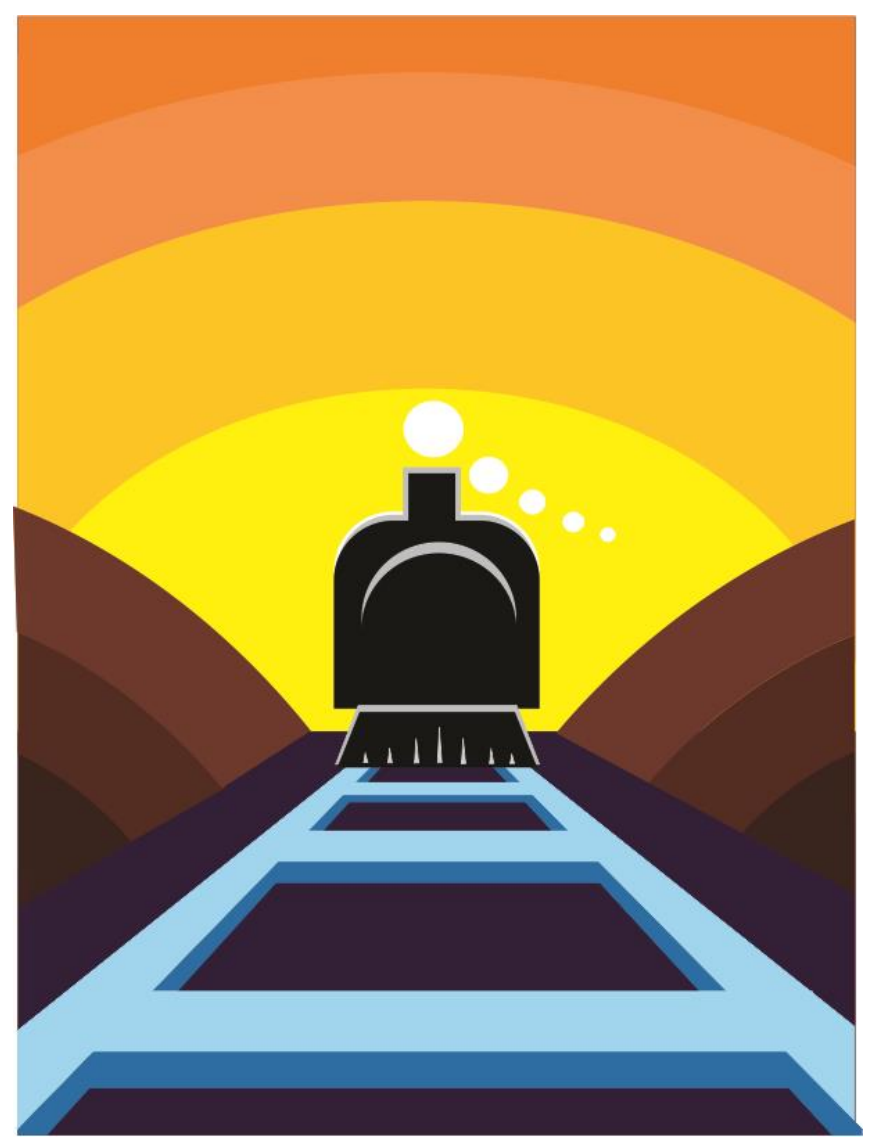

Fonte: acervo do pesquisador.

Criciúma ficou conhecida pela sua riqueza chamada "Ouro Negro", uma riqueza que the deu o título de "Capital do Carvão". A Maria Fumaça, como era chamado o Trem que levava o carvão da cidade, e que também servia de meio de transporte para muitos no movimento de ir e vir da cidade, marcava uma história de lutas e conquistas.

Figura 5 - Projeto escadaria bairro São Cristóvão - Criciúma, Santa Catarina. 


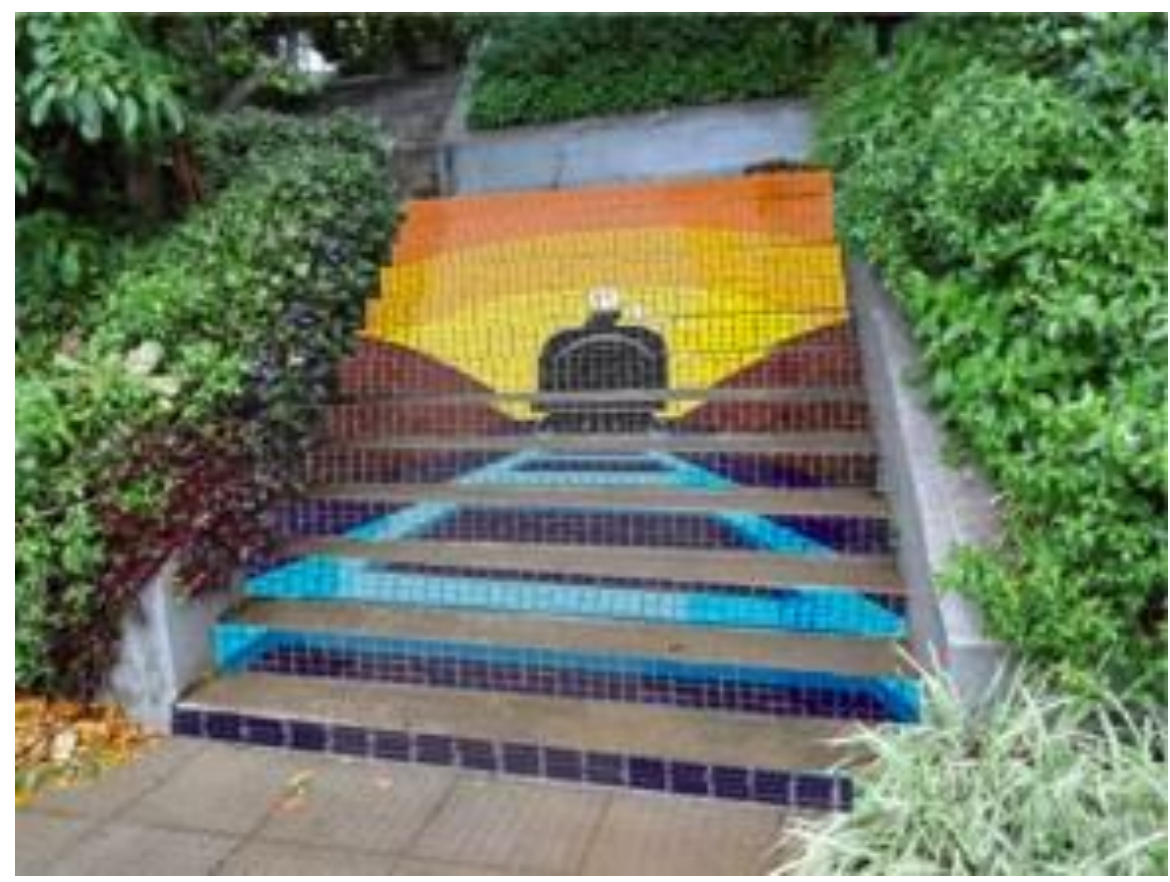

Fonte: acervo do pesquisador.

Fatos que podemos ver estampados nas palavras de um morador ao ver a arte final realizado a partir das entrevistas:

Eu como sendo morador já há 50 anos, vejo que realmente a ideia foi absorvida pelo grupo, ficou muito interessante a união do São Cristóvão (ícone) com essa movimentação que havia no local, toda a riqueza da cidade passava por nós e como éramos crianças, não sabíamos. Foi interessante retratar a questão dos trilhos. Sinto falta do trem claro, mas o progresso falou mais alto, foram arrancados os trilhos, e ainda existe o trem, mas muita gente sente falta. Por mim pode começar amanhã! (Edison Luiz Fernandes, 30 de setembro de 2014)

Além do trabalho desenvolvido no Bairro São Cristóvão - primeira experiência do projeto - o bairro Jardim União na região de atuação de projetos da Unesc denominada Paulo Freire, foi o segundo a ser trabalhado. Neste bairro, as pessoas entrevistadas tinham de 10 a 17 anos de tempo de moradia no lugar. Como perfil desta investigação, ouvir os moradores sobre seu lugar, remetemo-nos à Paulo Freire no que diz: "Ninguém educa ninguém, ninguém educa a si mesmo, os homens se educam entre si, mediatizados pelo mundo" (1994, p. 39). A troca de experiência na relação com os lugares da pesquisa, 
com as pessoas, seus saberes é que foram dando o caminho para as produções aqui apresentadas.

Foi relatado que ao longo dos anos não houveram mudanças significativas no local, sendo que atualmente, a região tem um índice elevado de criminalidade. Assim sendo, o que mais marcava aquelas pessoas eram os tempos que viviam tranquilos, em casas sem cercas, jogando bola e brincando pela rua. Os desenhos para os mosaicos foram elaborados então a partir desses relatos. As imagens criadas dialogam com a memória e os sentimentos destes motadores, resgantando aqueles tempos, que estes relembravam com saudosismo. Como na fala de um morador do bairro há 10 anos relata:

Eu sinto a falta das áreas com verde, com árvores, hoje não temos mais isso. Antigamente também ficávamos com as casa abertas, sem cercado. Hoje tem muito assalto, muito bandido, não dá pra bobear. (Everaldo dos Passos Morona, 28 de outubro de 2014).

Para Paulo Freire (1994, p. 10), "a palavra abre a consciência para o mundo comum das consciências, em diálogo portanto." É nesse exercício do diálogo que acontece a elaboração do desenho para o mosaico na escadaria do bairro Jardim União.

Figura 6 - Desenho escadaria bairro Jardim União - Criciúma, Santa Catarina. 

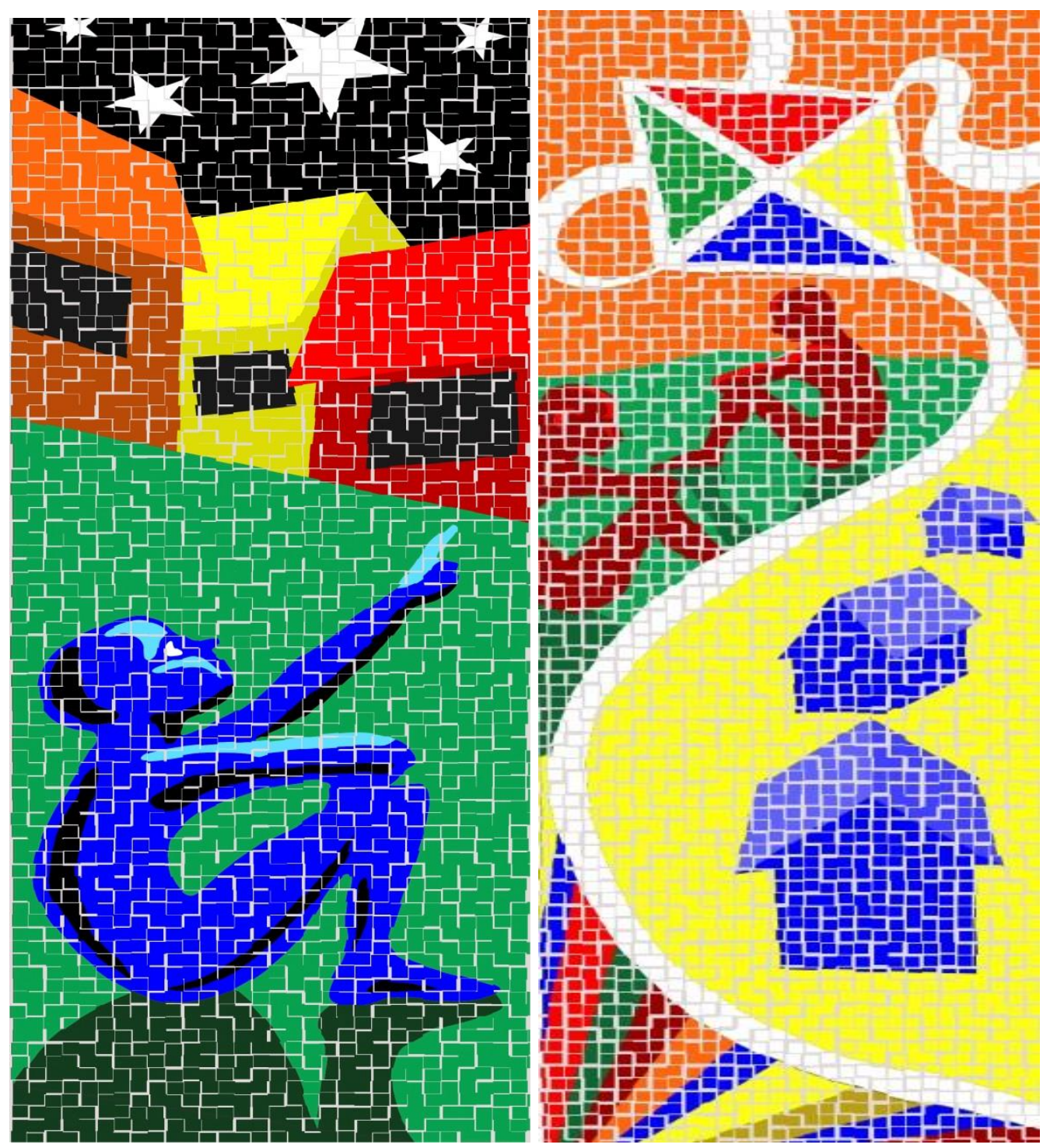

Fonte: arquivo do pesquisador

O projeto caminha por uma proposta que comunga com questões freiriana, no sentido de propor reflexões a partir do olhar para a cidade, um olhar que deixa marcas. Não marcas quaisquer. São marcas que identificam um lugar que tem história, um lugar que pela sua história constrói uma importância ímpar, que nesse caso, dialoga com o que afirma Feire:

A questão fundamental, neste caso, está em que, faltando aos homens uma compreensão crítica da totalidade em que estão, captando-a em pedaços nos quais não reconhecem a interação constituinte da mesma totalidade, não podem conhece-la. E não o podem porque, para conhece-la, seria necessário partir do ponto inverso. Isto é, Ihes seria indispensável ter antes a visão totalizada do 
contexto para, em seguida, separarem ou isolarem os elementos ou as parcialidades do contexto, através de cuja cisão voltariam com mais claridade à totalidade analisada. (1994, p. 56).

O que apresenta-se enquanto arte final nas escadarias do bairro, volta-se para um olhar o contexto com mais atenção e cuidado, como quem para, pensa, lembra e relembra histórias que compõem a realidade de uma comunidade que tem desejos.

Figura 7 - Projeto escadaria bairro Jardim União - Criciúma, Santa Catarina.

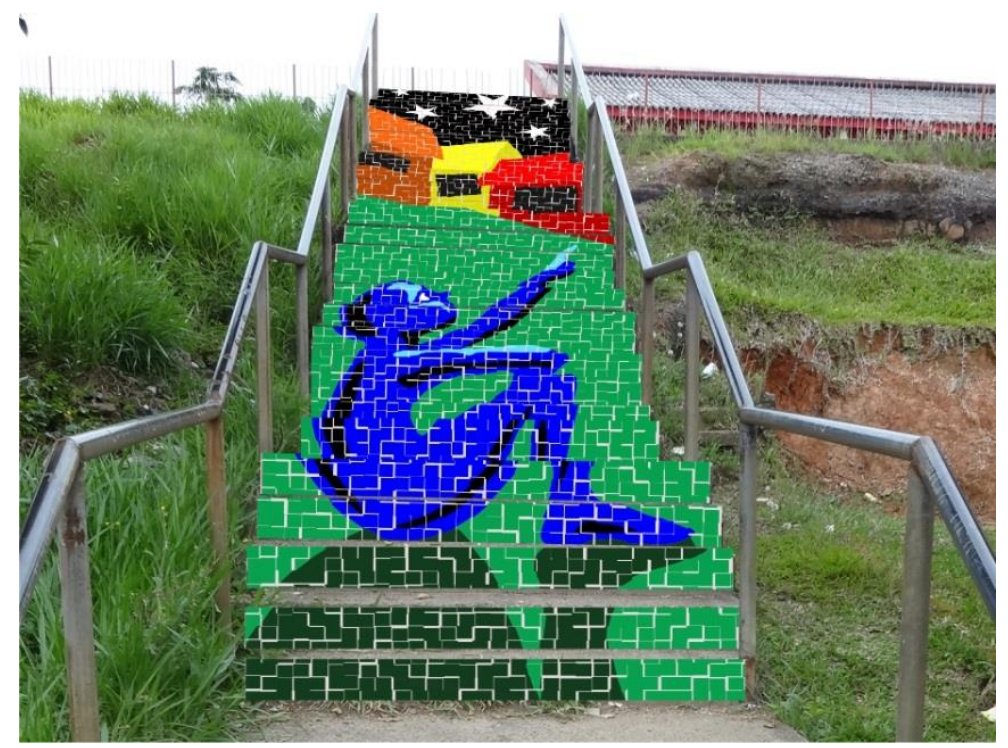

Fonte: arquivo do pesquisador

As escadarias do bairro vão contando sua história, partindo de desenhos elaborados pelas falas dos seus moradores.

Figura 8 - Projeto escadaria bairro Jardim União - Criciúma, Santa Catarina. 


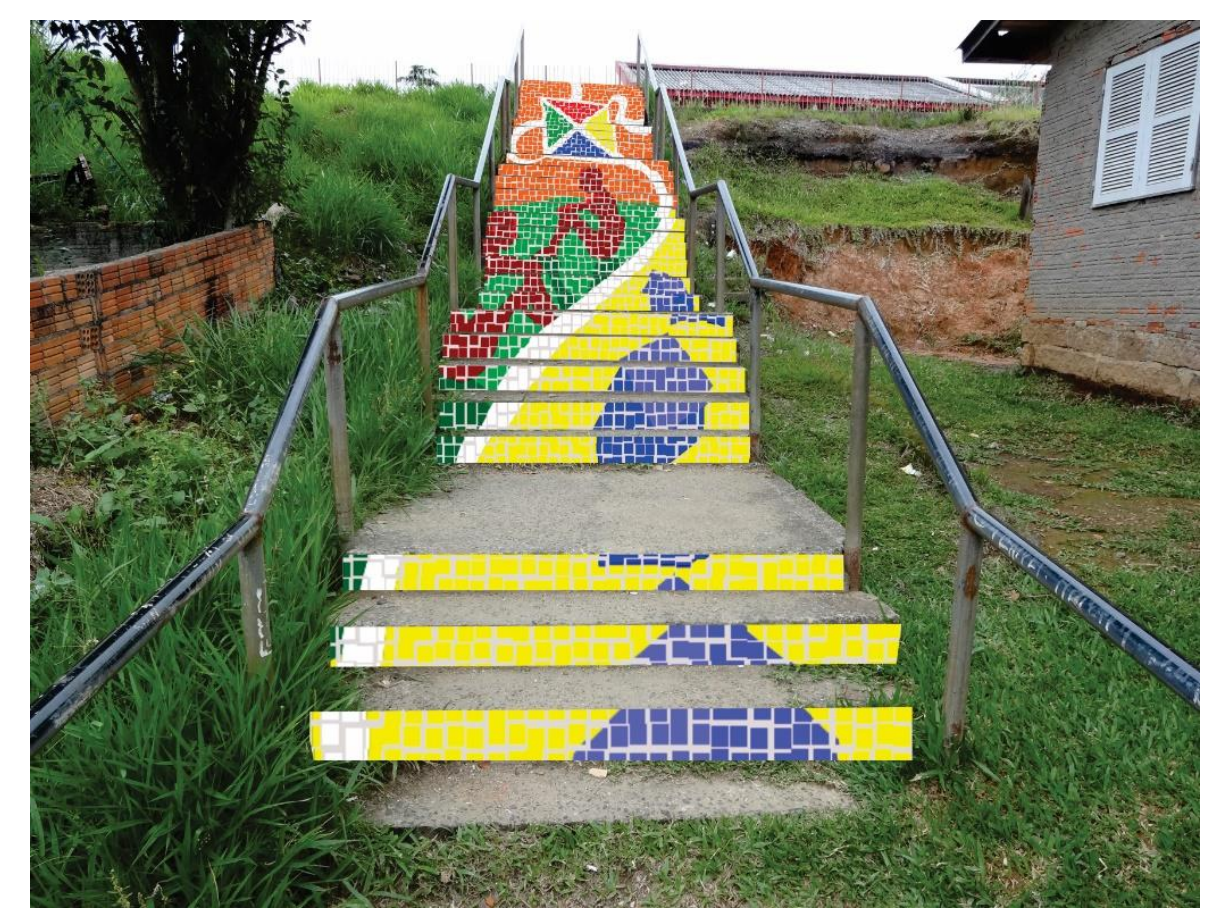

Fonte: arquivo do pesquisador

As entrevistas vão estampando uma estética elaborada a partir de ícones e movimentos de ir e vir das pessoas, criando assim uma estética popular vista, analisada e aprovada pelos seus moradores. Sobre Estética Popular Shusterman (1998) questiona o fato de a arte popular e a cultura de massa, que se mostram experiências estéticas recompensadoras, serem excluídas da discussão sobre arte, sendo as práticas acadêmicas filosóficas abstratas demais para essas diferentes expressões. Também discute como as perspectivas padronizadas de estética são hostis as condições que fazem surgir esse tipo de cultura popular. Assim sendo, busca-se uma legitimação desse tipo de arte, mesmo que não seja a ideal ou mais adequada, tornando a arte mais democrática e rompendo com pensamentos estéticos tradicionais. A elaboração de desenhos a partir da fala das pessoas sobre a história dos lugares onde moram pode ser um caminho para que uma visão estética se popularize criando marcas significativas na construção de um olhar cada vez mais crítico sobre o mundo em que vivemos e a cultura que nos marcam, e a qual deixamos nossas próprias marcas como sujeitos ativos que somos.

O autor começa relembrando o processo histórico da formação do debate estético, se eximindo de considerar certas ou erradas as teorias sobre 
arte, mas levantando a questão do "por quê?" e "como" essas teorias têm sido mal formuladas, iniciando com Platão. Preocupado em combater o poder da arte enquanto meio para se explicar o mundo e os acontecimentos da vida, Platão acaba sendo o primeiro a tentar fazer uma definição do que é arte. Porém seu objetivo nunca foi o de explicá-la como tal, mas unicamente depreciá-la, pois segundo ele, a arte seria uma mera imitação da vida (mimesis), impossibilitando o indivíduo de atingir a verdade última. Todas as outras teorias filosóficas que se seguem após a de Platão, ainda que não tratem a arte como algo pejorativo, continuam com esse conceito de separação com relação a vida real. No caso das escadarias, vamos ver um trabalho com vínculo direto à vida real, mas seria isso uma produção artística? Como os moradores veem essa proposta? Eles a consideram arte?

Para Shusterman (1998) as teorias seguintes concentravam-se sempre em analisar características salientes das obras, sendo elas geralmente muito amplas ou muito restritas. Logo, não tiveram sucesso em descobrir sua essência. Algumas delas, como a de Weitz, chegam a propor que se abandone o esforço de definir arte, dizendo que esta teria várias similaridades entre suas obras, mas que não haveria uma essência. Dickie (1970) questiona esse argumento, dizendo que as obras não têm uma propriedade comum específica, e que sua essência está no processo de criação. Para contrapor esta ideia, basta lembrar que existem objetos que surgem como obra de arte sem que haja esse objetivo inicial.

Já para Arthur Danto (1980), não haveria como encontrar uma definição exata, mas seu conceito estaria intimamente ligado as diferentes práticas artísticas através da história. Ao se abster da busca de sua essência, a arte estaria justamente abrindo espaço para que novas formas de expressão surjam, o que causa sua expansão (no que toca as práticas). Porém o ponto fraco desse argumento encontra-se na questão da falta de um discurso unificado, na eminência da contradição que tal definição causaria e na pura redução da teoria à análise histórica. Assim, não se poderiam especificar quais fatos ocasionam alterações no modo de produção artística, mas poderíamos, a partir dessas questões afirmarmos que os desenhos para os mosaicos nas escadarias da cidade seria um modo de expressar uma produção artística elaborada a partir de um coletivo de falas sobre o local onde essas escadarias 
estão situadas. Pois, todas estas teorias têm seu foco nas belas artes, herdando o pensamento de Platão de que a expressão artística está separada da vida, excluindo assim aquelas manifestações proveniente das massas, como dito antes, fora da abrangência dos estudos tradicionais. Em vista disso, Shusterman defende que se trabalhe com obras de arte que toquem a sensibilidade de quem interage com ela, para aproximar a experiência da arte, usando a estética pragmatista não para buscar uma definição absoluta da arte mas para visar sempre sua discussão.

Nesse sentido, ao coletar as falas das pessoas, produzir os desenhos e buscar a aprovação dessas pessoas para a elaboração dos mosaicos nas escadarias da cidade, temos o exercício de uma pesquisa, algo que se faz enquanto atividade elementar da ciência - e da arte - no seu questionamento e criação da realidade. É ela quem fornece insumos para a atividade de ensino e a renova diante dos desafios vindouros.

Ainda que seja uma atividade abstrata, a pesquisa inclui o pensar e o agir. Trata-se de uma pesquisa qualitativa que nos traz resposta sobre assuntos muito peculiares, envoltos com as ciências sociais, a qual tem sua preocupação tangível ao nível de realidade que não é possível de se qualificar. Exemplificando, significados, motivos, aspirações, crenças, valores e atitudes, itens estes que representam uma margem mais profunda das relações, dos processos e dos fenômenos que não possam ser resumidos a operacionalização de variáveis, porque estampam em desenhos alguns olhares sobre o local. Olhares esses, reorganizados pelas mãos de quem desenha.

No geral cientistas sociais lidam com dados estatísticos e captam deles apenas os fenômenos morfológicos, concretos ou visíveis, enquanto que o método qualitativo adentra na essência das ações humanas, algo não perceptível e não captável através de métodos matemáticos e estatísticos. Dados quantitativos e qualitativos não devem ser vistos em oposição, mas pelo contrário, como complemento um ao outro, pois há uma interação dinâmica entre estes dados que excluem suas diferenças.

Falamos aqui de uma pesquisa que busca materializar artisticamente - em desenhos e posteriormente em mosaicos - o pensamento das pessoas sobre a história que cercam o lugar onde moram. São histórias alimentadas pelo patrimônio material e imaterial que marcam o local, o lugar, o 
território no qual suas vidas se (re)organizam. Para melhor compreendermos a ideia de Patrimônio, um Patrimônio Cultural - que é do que a pesquisa trata encontramos no IPHAN", a informação de que "O Patrimônio Cultural pode ser definido como um bem (ou bens) de natureza material e imaterial considerado importante para a identidade da sociedade brasileira".

Encontramos ainda, que de acordo com o artigo 216 da Constituição Federal se caracteriza por patrimônio:

\begin{abstract}
As formas de expressão; os modos de criar; as criações científicas, artísticas e tecnológicas; as obras, objetos, documentos, edificações e demais espaços destinados às manifestações artístico-culturais; além de conjuntos urbanos e sítios de valor histórico, paisagístico, artístico, arqueológico, paleontológico, ecológico e científico. (Constituição da república federativa do Brasil de 1988)
\end{abstract}

Por patrimônio cultural imaterial podemos entender como as habilidades, as crenças, o modo de ser das pessoas e suas práticas, exemplificando como as manifestações literárias, musicais, plásticas, cênicas e lúdicas; rituais e festas que marcam a vivência coletiva da religiosidade, do entretenimento e de outras práticas da vida social; além de mercados, feiras, santuários, praças e demais espaços onde se concentram e se reproduzem práticas culturais. Podemos citar como patrimônio cultural imaterial brasileiro a manifestações literárias, musicais, plásticas, cênicas e lúdicas; rituais e festas que marcam a vivência coletiva da religiosidade, do entretenimento e de outras práticas da vida social; além de mercados, feiras, santuários, praças e demais espaços onde se concentram e se reproduzem práticas culturais (IPHAN, 2010).

Ao entrevistar os moradores dos bairros, faço alguns recortes das falas que evidenciam o que aqui compreendemos como patrimônio cultural imaterial: Valdnéia Gerônima, moradora do Bairro Jardim União, afirma que: "Antigamente o bairro se chamava tristeza... As ruas são as mesmas e a Legião da Boa Vontade é a única que auxilia as pessoas" (28 de outubro de 2014).

\footnotetext{
${ }^{3}$ www.iphan.gov.br
} 
Sobre patrimônio cultural material, o mesmo pode ser definido como um grupo de bens culturais classificados segundo a sua natureza: arqueológico, paisagístico e etnográfico; histórico; belas artes; e das artes aplicadas. Estão divididos entre bens móveis (núcleos urbanos, sítios arqueológicos e paisagísticos e bens individuais) e bens imóveis (coleções arqueológicas, acervos museológicos, documentais, bibliográficos, arquivísticos, ideográficos, fotográficos e cinematográficos). Podemos citar como patrimônios materiais brasileiros os conjuntos arquitetônicos de cidades como Ouro Preto (MG), Paraty (RJ), Olinda (PE) e São Luís (MA) ou paisagísticos, como Lençóis (BA), Serra do Curral (Belo Horizonte), Grutas do Lago Azul e de Nossa Senhora Aparecida (Bonito, MS) e o Corcovado (Rio de Janeiro). (IPHAN, 2010).

Nas entrevistas com os moradores sobre o que contam o lugar onde moram, surgiu algumas falas que evidenciam o patrimônio cultural material, como por exemplo, a fala de Edite Freitas:

\begin{abstract}
Antes, há muito tempo tinha aqui a linha do trem, e também a caixa de escolha de carvão, onde separavam o carvão bom do ruim. Também haviam muitos clubes (de dança) que eram o lugar onde as pessoas se divertiam. As minas de carvão muitas vezes eram usadas pelos jogadores do time local para fugir do treinamento e ir dançar. (Edite Freitas, Bairro São Cristóvão, Criciúma - SC,11 de outubro de 2014)
\end{abstract}

\title{
CONCLUSÃO
}

Durante estes levantamentos, foi possível captar olhares, sentimentos, lembranças, conteúdos ricos que adicionaram a pesquisa dados que irão auxiliar na formação e na investigação sobre como estes agentes se apropriam da sua cidade, cenário onde se passam os fatos de suas vidas e assim, sua própria história se confunde com a de seus espaços, mesclando-se com o patrimônio cultural.

Averiguou-se que os habitantes relatavam suas histórias com um saudosismo na fala, e por vezes um olhar distante, consultando na sua mente suas lembranças mais remotas. Quanto ao engajamento destas pessoas, houve uma oscilação entre aqueles que contribuíram com empolgação e outros 
que se limitaram a respostas curtas. Constata-se assim a noção de importância que cada um dá ao assunto, algo que pode estar relacionado as próprias experiências de cada um, ao seu conhecimento e entendimento sobre cultura, escolaridade e nível de renda. Não há como negar que alguns bairros ofereciam uma gama maior de elementos constantes como patrimônio cultural, enquanto que em contrapartida, outros contam com experiências triviais e cotidianas que não se enquadram nas atividades tradicionais da região (econômicas ou esportivas). Nestes se encontram uma sensibilidade maior nos relatos, estando estes mais ligados a sentimentos e expressões humanas. Ficam como contribuição estas falas, estas impressões e nuances que coletamos, que posteriormente, podem guiar políticas de promoção a cultura e ao bem estar em todas localidades. A pesquisa continua, e muitas descobertas, desenhos e conversas ainda estão por vir.

\section{REFERÊNCIAS}

PORTAL BRASIL. Conheça as diferenças, entre patrimônios materiais e imateriais. Disponível em: < http://www.brasil.gov.br/cultura/2009/10/conheca-as-diferencas-entrepatrimonios-materiais-e-imateriais> Acesso em: 24 abr.2015.

FREIRE, Paulo. Pedagogia do Oprimido. $11^{\text {a }}$ ed. Ed. Paz e Terra. Rio de Janeiro: 1994.

SCHUSTERMAN, Richard. Vivendo a arte: o pensamento pragmatista e a estética popular. São Paulo: Editora 34, 1998.

MINAYO, Maria Cecília de Souza. Pesquisa social: teoria, método e

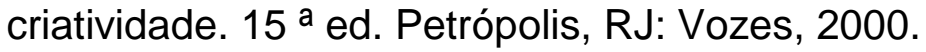

